\title{
Article \\ Three-Way Multi-Attribute Decision Making Based on Outranking Relations under Intuitionistic Fuzzy Environments
}

\author{
Zengtai Gong * and Le Fan
}

check for updates

Citation: Gong, Z.; Fan, L.

Three-Way Multi-Attribute Decision

Making Based on Outranking

Relations under Intuitionistic Fuzzy

Environments. Symmetry 2021, 13,

1384. https://doi.org/10.3390/

sym 13081384

Academic Editor: Basil Papadopoulos

Received: 2 July 2021

Accepted: 20 July 2021

Published: 29 July 2021

Publisher's Note: MDPI stays neutral with regard to jurisdictional claims in published maps and institutional affiliations.

Copyright: (c) 2021 by the authors. Licensee MDPI, Basel, Switzerland. This article is an open access article distributed under the terms and conditions of the Creative Commons Attribution (CC BY) license (https:// creativecommons.org/licenses/by/ $4.0 /)$.
College of Mathematics and Statistics, Northwest Normal University, Lanzhou 730070, China; fanle17@163.com

* Correspondence: gongzt@nwnu.edu.cn

\begin{abstract}
With the increasing complexity of the human social environment, it is impossible to describe each object in detail with accurate numbers when solving multiple attribute decisionmaking (MADM) problems. Compared with the fuzzy set (FS), the intuitionistic fuzzy set (IFS) not only has obvious advantages in allocating ambiguous values to the object to be considered, but also takes into account the degree of membership and non-membership, so it is more suitable for decision makers (DMs) to deal with complex realistic problems. Therefore, it is of great significance to propose a MADM method under an intuitionistic fuzzy environment. Moreover, compared with the traditional 2WD, by putting forward the option of delay, the decision-making risk can be effectively reduced using three-way decision (3WD). In addition, the binary relations between objects in the decision-making process have been continuously generalized, such as equivalence relation which have symmetrical relationship, dominance relation and outranking relation, which are worthy of study. In this paper, we propose 3WD-MADM method based on IF environment and the objective IFS is calculated by using the information table. Then, the hybrid information table is used to solve the supplier selection problem to demonstrate the effectiveness of the proposed method.
\end{abstract}

Keywords: outranking relation; three-way decision; intuitionistic fuzzy set; IF loss function; IF MADM

\section{Introduction}

Selecting one of these alternatives based on the information provided in real life is the main purpose of MADM, which is to rank a series of alternatives and determine the best one. In addition, in the face of different types of attributes, it is extremely important to make reasonable decision results when dealing with MADM problems. Many scholars have gone deep into MADM and made remarkable achievements in all aspects. There are a number of classical approaches to deal with MADM problems, such as the VIKOR method [1,2], the TOPSIS method which is used to find the alternative that is closest to the positive ideal solution and farthest from the negative ideal solution [3], ELECTRE method is designed to construct the outranking relationship of alternatives [4], Vinogradova provided MADM methods as a component of mathematics-based optimization [5], Chen et al. [6] used hybrid MADM model to evaluate and improve the performance of product design, etc. However, most methods seldom consider the delay of decision-making, which will increase the risk of decision-making. In order to make up for this shortcoming, Zhan et al. [7] used the 3WD theory to solve MADM problems and put forward a vaild decision rule.

The researches which were reported in [8-11] inspired that IFSs, put forward by Atanassov [12], are as well as a crucial evaluation form aiming to describe the uncertainty. The original fuzzy set only considers membership degree [13-15], however, IFS has the characteristics of both membership degree and non-membership degree [12], it provides a more reasonable method to describe uncertainty. In recent years, intuitionistic fuzzy values (IFVs) and intuitionistic fuzzy set (IFS) are deeply developed and studied, for example, Chen [16] clarified the positive and negative evaluation effects (or optimism and pessimism). Considering a combination of ELECTRE and VIKOR, Cali et al. [17] 
developed a novel outranking based multi criteria group decision making. Liu [18] defined an evaluation function for the decision-making problem to measure the degrees and presented the concept of intuitionistic fuzzy point operators. Du [19] studied the subtraction and division operations over intuitionistic fuzzy values which derived from the Hamming distance between them by the optimization method. Yang [20] investigated two possible solutions to the problem of constructing a shadowed set from an Atanassov intuitionistic fuzzy set. Gao et al. [21] proposed a novel target threat assessment method under intuitionistic fuzzy multi-attribute decision making environment. Zou et al. [22] used a linguistic-valued intuitionistic fuzzy formal decision context to solve the individual financial investment problem.

Compared with fuzzy information and accurate information, intuitionistic fuzzy information can summarize and describe the uncertain and complex fuzzy characteristics more comprehensively in the process of multi-attribute decision-making so that decision makers can obtain more comprehensive, real and effective information, and reduce decision-making errors caused by incomplete information. Furthermore, intuitionistic fuzzy information has compressibility, in which the decision makers can process, organize, summarize information. In addition, decision makers can deal with intuitionistic fuzzy information by appropriate methods, which can reduce the loss of effective information and enable decision makers to make scientific decisions. For example, based on intuitionistic fuzzy environment, Ecer [23] used MARCOS technique to make decisions and rank insurance companies, Kumar [24] proposed a novel IF-reliability approach to evaluate failure probability of the system, etc. [18,25-27].

Yao's scientific and reasonable explanation for 3WD is derived from Decision-theoretic rough sets (DTRSs), which, on the basis of Bayesian minimum risk, is able to make decisions through actual semantics [28]. The theory of 3WD, started by Yao [29], is regarded as a trisecting-acting-outcome (TAO). 3WD extends the usual 2WD (accept or reject) model though adding a non-commitment option. In addition, in the course of medical diagnosis, for instance, doctors often use the 3WD method aiming to make decisions. In other words, doctors could decide to treat, not treat, or keep patients under observation according to patients'symptom. The attitude towards an object depends on which domain it is in, the attitude of acceptance in the positive domain, the attitude of rejection in the negative domain, the attitude of relaxation in the boundary domain. It is a new perspective of tolerance for error which fits our habit of thinking under uncertainty. So, 3WD, based on DTRSs, has drawn the attention of scholars and gotten rapid development since its birth. For example, investment options [30], medical diagnosis [31], environmental managements [32], energy project selection [8], infectious disease diagnosis problem [33], etc.

In a word, the combination of 3WD and MADM is a new direction for further research in this paper. Particularly, a 3WD method, under IF environments, is intended to be put forward via outranking relationships and decision risks. A hybrid information table has been put forward by the combination of IF MADM matrix and loss function table. Furthermore, we also make use of the proposed 3WD method to solve a supplier selection problem.

\section{Preliminaries}

In this section, we briefly review some concepts of IFSs, Bayesian decision procedures and the ELECTRE method.

\subsection{Intuitionistic Fuzzy Set}

Definition 1 ([12]). Let $U$ be a universal set and an IFS $X$ is represented as:

$$
X=\left\{\left\langle a, \mu_{X}(a), v_{X}(a)\right\rangle \mid a \in U\right\},
$$

where $\mu_{X}, v_{X}: U \longrightarrow[0,1]$, such that $\mu_{X}(a)+v_{X}(a) \leq 1, a \in U$. Here, $\mu_{X}(a), v_{X}(a)$, respectively, stand for the membership degree and non-membership degree of a to $X$. The hesitancy degree of $a \in U$ is given by $\pi_{X}(a)=1-\mu_{X}(a)-v_{X}(a)$. According to the notations reported 
in [34,35], $\alpha=\left(\mu_{\alpha}, v_{\alpha}\right)$ is named as intuitionistic fuzzy value(IFV), which satisfies $0 \leq \mu_{\alpha}, v_{\alpha} \leq 1$ and $0 \leq \mu_{\alpha}+v_{\alpha} \leq 1$.

Example 1. Let $X$ be an IF concept of youth and the set of alternatives be $U=\left\{a_{1}, a_{2}, a_{3}\right\}$. The IFVs $\alpha_{1}=\left(\mu_{\alpha_{1}}, v_{\alpha_{1}}\right)=(0.6,0.4), \alpha_{2}=\left(\mu_{\alpha_{2}}, v_{\alpha_{2}}\right)=(0.6,0.2), \alpha_{3}=\left(\mu_{\alpha_{3}}, v_{\alpha_{3}}\right)=(0.6,0)$ represent the membership degree and non-membership degree of the concept of youth for each alternative, respectively. According to $\pi_{X}\left(a_{1}\right)=1-0.6-0.4=0, \pi_{X}\left(a_{2}\right)=1-0.6-0.2=0.2$ and $\pi_{X}\left(a_{3}\right)=1-0.6-0=0.4$, the alternative $a_{1}$ in $U$ is certain and alternatives $a_{2}$ and $a_{3}$ are uncertain. Moreover, by comparison we have $\pi_{X}\left(a_{2}\right)<\pi_{X}\left(a_{3}\right)$.

Definition 2 ([12,34,36,37]). Given two IFVs $\alpha=\left(\mu_{\alpha}, v_{\alpha}\right), \beta=\left(\mu_{\beta}, v_{\beta}\right)$ and a positive real number $\lambda$, some operations can be defined as follows:

(1) $\bar{\alpha}=\left(v_{\alpha}, \mu_{\alpha}\right)$;

(2) $\alpha \oplus \beta=\left(\mu_{\alpha}+\mu_{\beta}-\mu_{\alpha} \mu_{\beta}, v_{\alpha} v_{\beta}\right)=\left(1-\left(1-\mu_{\alpha}\right)\left(1-\mu_{\beta}\right), v_{\alpha} v_{\beta}\right)$;

(3) $\alpha \otimes \beta=\left(\mu_{\alpha} \mu_{\beta}, 1-\left(1-v_{\alpha}\right)\left(1-v_{\beta}\right)\right)$;

(4) $\lambda \alpha=\left(1-\left(1-\mu_{\alpha}\right)^{\lambda}, v_{\alpha}^{\lambda}\right)$

(5) $\alpha^{\lambda}=\left(\mu_{\alpha}^{\lambda}, 1-\left(1-v_{\alpha}\right)^{\lambda}\right)$;

(6) (Distance function) $d(\alpha, \beta)=\frac{1}{2}\left(\left|\mu_{\alpha}-\mu_{\beta}\right|+\left|v_{\alpha}-v_{\beta}\right|+\left|\mu_{\beta}+v_{\beta}-\mu_{\alpha}-v_{\alpha}\right|\right)$;

(7) $\alpha \ominus \beta=\left(\widetilde{\mu_{\alpha \ominus \beta}}, \widetilde{v_{\alpha \ominus \beta}}\right)$, where

$$
\widetilde{\mu_{\alpha \ominus \beta}}= \begin{cases}\frac{\mu_{\alpha}-\mu_{\beta}}{1-\mu_{\beta}}, & \text { if } \mu_{\alpha} \geq \mu_{\beta} \text { and } v_{\alpha} \leq v_{\beta} \text { and } v_{\beta}>0 \text { and } v_{\alpha} \pi_{\beta} \leq \pi_{\alpha} v_{\beta} \\ 0, & \text { otherwise }\end{cases}
$$

and

$$
\widetilde{v_{\alpha \ominus \beta}}= \begin{cases}\frac{v_{\alpha}}{v_{\beta}}, & \text { if } \mu_{\alpha} \geq \mu_{\beta} \text { and } v_{\alpha} \leq v_{\beta} \text { and } v_{\beta}>0 \text { and } v_{\alpha} \pi_{\beta} \leq \pi_{\alpha} v_{\beta} \\ 1, & \text { otherwise }\end{cases}
$$

(8) $\alpha \oslash \beta=\left(\widetilde{\mu_{\alpha \oslash \beta}}, \widetilde{v_{\alpha \oslash \beta}}\right)$, where

$$
\widetilde{\mu_{\alpha \oslash \beta}}= \begin{cases}\frac{\mu_{\alpha}}{\mu_{\beta}}, & \text { if } \mu_{\alpha} \leq \mu_{\beta} \text { and } v_{\alpha} \geq v_{\beta} \text { and } \mu_{\beta}>0 \text { and } \mu_{\alpha} \pi_{\beta} \leq \pi_{\alpha} \mu_{\beta} \\ 0, & \text { otherwise }\end{cases}
$$

and

$$
\widetilde{v_{\alpha \oslash \beta}}= \begin{cases}\frac{v_{\alpha}-v_{\beta}}{1-v_{\beta}}, & \text { if } \mu_{\alpha} \leq \mu_{\beta} \text { and } v_{\alpha} \geq v_{\beta} \text { and } \mu_{\beta}>0 \text { and } \mu_{\alpha} \pi_{\beta} \leq \pi_{\alpha} \mu_{\beta} \\ 1, & \text { otherwise }\end{cases}
$$

Definition 3 ([25]). Let an IFV $\alpha=\left(\mu_{\alpha}, v_{\alpha}\right)$, then the score function of $\alpha$ is calculated as:

$$
S(\alpha)=\mu_{\alpha}-v_{\alpha}
$$

The accuracy function of $\alpha$ is defined as

$$
H(\alpha)=\mu_{\alpha}+v_{\alpha}
$$

where $-1 \leq S(\alpha) \leq 1$ and $0 \leq H(\alpha) \leq 1$

Definition 4 ([25]). Given two IFVs $\alpha=\left(\mu_{\alpha}, v_{\alpha}\right)$ and $\beta=\left(\mu_{\beta}, v_{\beta}\right)$, we confirm their relationships below:

(1) If $S(\alpha)>S(\beta)$, then $\beta$ is smaller than $\alpha$, denoted by $\alpha \succ \beta$;

(2) If $S(\alpha)<S(\beta)$, then $\alpha$ is smaller than $\beta$, denoted by $\alpha \prec \beta$;

(3) If $S(\alpha)=S(\beta)$, then

(i) If $H(\alpha)=H(\beta)$, then $\alpha$ is equal to $\beta$, denoted by $\alpha=\beta$; 
(ii) If $H(\alpha)>H(\beta)$, then $\beta$ is smaller than $\alpha$, denoted by $\alpha \succ \beta$;

(iii) If $H(\alpha)<H(\beta)$, then $\alpha$ is smaller than $\beta$, denoted by $\alpha \prec \beta$.

Proposition 1. Let $\alpha_{1}, \alpha_{2}$ be two IFVs, when $\mu_{\alpha_{1}} \geq \mu_{\alpha_{2}}, v_{\alpha_{1}} \leq v_{\alpha_{2}}, v_{\alpha_{2}}>0$ and $v_{\alpha_{1}} \pi_{\alpha_{2}} \leq$ $\pi_{\alpha_{1}} v_{\alpha_{2}}$, we have the equation:

$$
\left(\alpha_{1} \ominus \alpha_{2}\right) \oplus \alpha_{2}=\alpha_{1}
$$

Proof. For two IFVs $\alpha_{1}$ and $\alpha_{2}$, we have

$$
\begin{aligned}
& \left(\alpha_{1} \ominus \alpha_{2}\right) \oplus \alpha_{2} \\
= & \left(\frac{\mu_{\alpha_{1}}-\mu_{\alpha_{2}}}{1-\mu_{\alpha_{2}}}, \frac{v_{\alpha_{1}}}{\mu_{\alpha_{2}}}\right) \oplus\left(\mu_{\alpha_{2}}, v_{\alpha_{2}}\right) \\
= & \left(1-\left(1-\frac{\mu_{\alpha_{1}}-\mu_{\alpha_{2}}}{1-\mu_{\alpha_{2}}}\right)\left(1-\mu_{\alpha_{2}}\right), \frac{v_{\alpha_{1}}}{v_{\alpha_{2}}}\right) \\
= & \left(1-\left(1-\mu_{\alpha_{2}}-\mu_{\alpha_{1}}+\mu_{\alpha_{2}}\right), v_{\alpha_{1}}\right) \\
= & \left(\mu_{\alpha_{1}}, v_{\alpha_{1}}\right) \\
= & \alpha_{1} .
\end{aligned}
$$

Proposition 2. Let $\alpha_{1}, \alpha_{2}$ be two IFVs, when $\mu_{\alpha_{1}}<\mu_{\alpha_{2}}$ or $v_{\alpha_{1}}>v_{\alpha_{2}}$ or $v_{\alpha_{2}} \leq 0$ or $v_{\alpha_{1}} \pi_{\alpha_{2}}>$ $\pi_{\alpha_{1}} v_{\alpha_{2}}$, we have the equation:

$$
\left(\alpha_{1} \ominus \alpha_{2}\right) \oplus \alpha_{2}=\alpha_{2}
$$

Proof. For two IFVs $\alpha_{1}$ and $\alpha_{2}$, we have

$$
\begin{aligned}
& \left(\alpha_{1} \ominus \alpha_{2}\right) \oplus \alpha_{2} \\
= & (0,1) \oplus\left(\mu_{\alpha_{2}}, v_{\alpha_{2}}\right) \\
= & \left(1-(1-0)\left(1-\mu_{\alpha_{2}}\right), 1 v_{\alpha_{2}}\right) \\
= & \left(\mu_{\alpha_{2}}, v_{\alpha_{2}}\right) \\
= & \alpha_{2} .
\end{aligned}
$$

Definition 5. For an IFV $\alpha$, the negative operation of $\alpha$ can be defined as follows:

$$
\neg \alpha=(1,0) \ominus \alpha .
$$

According to Propositions 1 and 2, we obtain $\neg \alpha \oplus \alpha=(1,0)$.

\section{2. $3 W D$}

Let $U$ be a set of alternatives. For any $X \subseteq U$, let $\Phi=\{X, \neg X\}$ be the state set of alternatives which means each alternative $a \in U$ or not. $A=\left\{a_{P}, a_{B}, a_{N}\right\}$ is the action set, where $a_{P}, a_{B}$ and $a_{P}$ denote $a \in \operatorname{POS}(X), a \in B N D(X)$ and $a \in N E G(X)$.

For any alternative $a \in U$, the expected loss funtions associated with taking three actions $R\left(a_{\bowtie} \mid[a]_{R}\right)(\bowtie=P, B, N)$ as follows [8]:

$$
\begin{aligned}
& R\left(a_{P} \mid[a]_{R}\right)=\chi_{P P} P\left(X \mid[a]_{R}\right)+\chi_{P N} P\left(\neg X \mid[a]_{R}\right), \\
& R\left(a_{B} \mid[a]_{R}\right)=\chi_{B P} P\left(X \mid[a]_{R}\right)+\chi_{B N} P\left(\neg X \mid[a]_{R}\right), \\
& R\left(a_{N} \mid[a]_{R}\right)=\chi_{N P} P\left(X \mid[a]_{R}\right)+\chi_{N N} P\left(\neg X \mid[a]_{R}\right),
\end{aligned}
$$

where $[a]_{R}$ represents the equivalence class that contains $a, \chi_{P P}, \chi_{B P}$ and $\chi_{N P}$ represent the loss function of actions $a_{P}, a_{B}$ and $a_{N}$ when $a$ belongs to $X$, respectively. Analogously, 
$\chi_{P N}, \chi_{B N}$ and $\chi_{N N}$ denote the loss function of actions $a_{P}, a_{B}$ and $a_{N}$ when $a$ belongs to $\neg X$, respectively.

For any $A \subseteq U, P\left(A \mid[a]_{R}\right)$ represents the conditional probability of an alternative $a$. By virtue of the properties of the conditional probability, we have:

$$
P\left(A \mid[a]_{R}\right)+P\left(\neg A \mid[a]_{R}\right)=1 .
$$

According to the realistic explanation of the loss functions, we can get

$$
\chi_{P P} \leq \chi_{B P}<\chi_{N P} \text { and } \chi_{P N}>\chi_{B N} \geq \chi_{N N} .
$$

the following decision rules are given via Bayesian theory:

(P) If $R\left(a_{P} \mid[a]_{R}\right)<R\left(a_{B} \mid[a]_{R}\right)$ and $R\left(a_{P} \mid[a]_{R}\right)<R\left(a_{N} \mid[a]_{R}\right)$, then $a \in \operatorname{POS}(X)$,

(B) If $R\left(a_{B} \mid[a]_{R}\right)<R\left(a_{P} \mid[a]_{R}\right)$ and $R\left(a_{B} \mid[a]_{R}\right)<R\left(a_{N} \mid[a]_{R}\right)$, then $a \in B N D(X)$,

(N) If $R\left(a_{N} \mid[a]_{R}\right)<R\left(a_{P} \mid[a]_{R}\right)$ and $R\left(a_{N} \mid[a]_{R}\right)<R\left(a_{B} \mid[a]_{R}\right)$, then $a \in N E G(X)$.

\subsection{The Determination of an Outranking Relation by the ELECTRE-I Method}

In 1969, Roy [38] proposed the ELECTRE-I method, which process some choice problems in MADM. Let $U=\left\{a_{1}, a_{2}, \ldots, a_{n}\right\}$ be an alternative set, $C=\left\{A_{1}, A_{2}, \ldots, A_{m}\right\}$ be an attribute set and $\mathcal{W}=\left\{\omega_{1}, \omega_{2}, \ldots, \omega_{m}\right\}$ be a weight vector. The ELECTRE-I method constructs an outranking relation based on the following steps:

- Construction of three indicator sets

$$
\begin{aligned}
& J_{i t}^{+}=\left\{j \mid j=1,2, \ldots, m, A_{i j}>A_{t j}\right\}, \\
& J_{i t}^{=}=\left\{j \mid j=1,2, \ldots, m, A_{i j}=A_{t j}\right\}, \\
& J_{i t}^{-}=\left\{j \mid j=1,2, \ldots, m, A_{i j}<A_{t j}\right\},
\end{aligned}
$$

where $A_{i j}$ is the evaluation value of the alternative $a_{i}$ under the attribute $A_{j}$.

- Calculation of the concordance index

$$
\begin{gathered}
J_{i t}=\sum_{j \in J_{i t}^{+}} \omega_{j}+\sum_{j \in J_{i t}^{\bar{E}}} \omega_{j}, \\
\overline{J_{i t}}=\frac{\sum_{j \in J_{i t}^{+}} \omega_{j}}{\sum_{j \in J_{i t}^{-}} \omega_{j}} .
\end{gathered}
$$

- Concordance test

Set $\delta \in(0.5,1]$, if the alternatives $a_{i}$ and $a_{t}$ meet the conditions $J_{i t} \geq \delta$ and $\overline{J_{i t}} \geq 1$, it passes the concordance test. The lager the value of $\delta$, the stricter the requirement that $a_{i}$ is superior to $a_{t}$.

- Calculation of discordance index

$$
G_{i t}=\max _{j=1,2, \ldots, m}\left\{\frac{A_{i j}-A_{t j}}{p}\right\},
$$

where $p$ denotes a given veto threshold.

- Non-discordance test

If the alternatives $a_{i}$ and $a_{t}$ satisfy requirement $G_{i t} \leq 1$, it passes the nondiscordance test.

- The determination of the outranking relationship

If the alternatives $a_{i}$ and $a_{t}$ pass both the concordance test and the non-discordance test, i.e., $J_{i t} \geq \delta, \overline{J_{i t}} \geq 1$ and $G_{i t} \leq 1$, then the alternative $a_{i}$ outranks the alternative $a_{t}$, denoted as $a_{i} S a_{t}$. 


\section{A New 3WD Method under IF Environments}

Next, we will obtain the objective IFS $X$, outranking relations via ELECTRE method and the conditional probability based on IF environments. Finally, we build the decisiontheoretic rough intuitionistic fuzzy set(DTRIFS) model.

\subsection{The Determination of IFSs}

In general, both FS and IFS are given subjectively, which obviously will have subjective influence in the decision-making process. Therefore, we intend to objectively calculate IFS based on the IF information table. The specific process is as follows:

Let $U=\left\{a_{1}, a_{2}, \ldots, a_{n}\right\}, C=\left\{A_{1}, A_{2}, \ldots, A_{m}\right\}$ and $E=\left\{E_{1}, E_{2}, \ldots, E_{k}\right\}$ represent $n$ alternatives, $m$ attributes and $k$ experts. The IF-multi-attribute information table is given in Table 1. Aggregated IF-multi-attribute information is given in Table 2.

Table 1. The IF-multi-attribute information table of k experts.

\begin{tabular}{llllll}
\hline & & $A_{\mathbf{1}}$ & $A_{\mathbf{2}}$ & $\cdots$ & $A_{m}$ \\
\hline \multirow{3}{*}{$R^{1}=$} & $\alpha_{11}^{1}$ & $\alpha_{12}^{1}$ & $\cdots$ & $\alpha_{1 m}^{1}$ \\
$\vdots$ & $a_{1}$ & $\vdots$ & $\vdots$ & $\cdots$ & $\vdots$ \\
$R^{k}=$ & $\alpha_{n 1}^{1}$ & $\alpha_{n 2}^{1}$ & $\cdots$ & $\alpha_{n m}^{1}$ \\
& $\vdots$ & $\vdots$ & $\vdots$ & $\cdots$ & $\vdots$ \\
\cline { 2 - 6 } & $\vdots$ & $\alpha_{11}^{k}$ & $\alpha_{12}^{k}$ & $\cdots$ & $\alpha_{1 m}^{k}$ \\
& $\vdots$ & $\vdots$ & $\vdots$ & $\cdots$ & $\vdots$ \\
& $a_{1}$ & $\alpha_{n 1}^{k}$ & $\alpha_{n 2}^{k}$ & $\cdots$ & $\alpha_{n m}^{k}$ \\
& $a_{n}$ & $\omega_{1}$ & $\omega_{2}$ & $\cdots$ & $\omega_{m}$ \\
\hline
\end{tabular}

Table 2. Aggregated IF-multi-attribute information table.

\begin{tabular}{lllll}
\hline & $A_{\mathbf{1}}$ & $A_{\mathbf{2}}$ & $\cdots$ & $A_{m}$ \\
\hline$a_{1}$ & $\beta_{11}$ & $\beta_{12}$ & $\cdots$ & $\beta_{1 m}$ \\
$\vdots$ & $\vdots$ & $\vdots$ & $\cdots$ & $\vdots$ \\
$a_{n}$ & $\beta_{n 1}$ & $\beta_{n 2}$ & $\cdots$ & $\beta_{n m}$ \\
$\mathcal{W}$ & $\omega_{1}$ & $\omega_{2}$ & $\cdots$ & $\omega_{m}$ \\
\hline
\end{tabular}

In Table $1, \alpha_{i j}^{l}(i=1,2, \ldots, n, j=1,2, \ldots, m, l=1,2, \ldots, k)$ are IFVs which denote the evaluation value of the alternative $a_{i}$ by the lth expert under the attribute $A_{j}$. The weight of the attribute $A_{j}$ and the expert $E_{l}$ are indicated by $\omega_{j}$ and $\tau_{l}$. Here, $\sum_{j=1}^{m} \omega_{j}=1, \sum_{l=1}^{k} \tau_{l}=1$.

According to the IF matrix and the IFWA aggregation operator, the IFS $X$ can be determined as follows:

$$
\begin{aligned}
\beta_{i j} & =I F W A\left(\alpha_{i j}^{1}, \alpha_{i j}^{2}, \ldots, \alpha_{i j}^{k}\right)=\tau_{1} \alpha_{i j}^{1} \bigoplus \tau_{2} \alpha_{i j}^{2} \bigoplus \ldots \bigoplus \tau_{k} \alpha_{i j}^{k} \\
& =\left(1-\prod_{l=1}^{k}\left(1-\mu_{i j}^{l}\right)^{\tau_{l}}, \prod_{l=1}^{k}\left(v_{i j}^{l}\right)^{\tau_{l}}\right)
\end{aligned}
$$

$$
\begin{aligned}
X & =\frac{\omega_{1} \beta_{11} \oplus \ldots \oplus \omega_{m} \beta_{1 m}}{a_{1}}+\frac{\omega_{2} \beta_{21} \oplus \ldots \oplus \omega_{m} \beta_{2 m}}{a_{2}}+\ldots+\frac{\omega_{1} \beta_{n 1} \oplus \ldots \oplus \omega_{m} \beta_{n m}}{a_{n}} \\
& =\sum_{i=1}^{n} \frac{\bigoplus_{j=1}^{m} \omega_{j} \beta_{i j}}{a_{i}} .
\end{aligned}
$$

These terms are well explained in the following example: 
Example 2 ([17]). Table 3 is an IF multi-attribute information table given by three experts. Suppose that $U=\left\{a_{1}, a_{2}, a_{3}\right\}$ is a set of three alternatives and five criteria $C=\left\{A_{1}, A_{2}, A_{3}, A_{4}, A_{5}\right\}$. The weights of three experts are $0.369,0.330$ and 0.301 , respectively. The value of each expert's assessment of each alternative $a_{i}$ with respect to attribute $A_{j}$ is given in Table 3:

Table 3. The IF-multi-attribute information table of schemes.

\begin{tabular}{ccccccc}
\hline & & $A_{\mathbf{1}}$ & $\boldsymbol{A}_{\mathbf{2}}$ & $\boldsymbol{A}_{\mathbf{3}}$ & $\boldsymbol{A}_{\mathbf{4}}$ & $\boldsymbol{A}_{\mathbf{5}}$ \\
\hline \multirow{3}{*}{$R^{1}=$} & $a_{1}$ & $(0.60,0.30)$ & $(0.70,0.20)$ & $(0.50,0.40)$ & $(0.80,0.10)$ & $(0.50,0.40)$ \\
& $a_{2}$ & $(0.70,0.20)$ & $(0.80,0.10)$ & $(0.80,0.10)$ & $(0.80,0.10)$ & $(0.80,0.10)$ \\
$R^{2}=$ & $(0.80,0.10)$ & $(0.60,0.30)$ & $(0.70,0.20)$ & $(0.70,0.20)$ & $(0.70,0.20)$ \\
\cline { 2 - 7 }$a_{3}$ & $a_{1}$ & $(0.70,0.20)$ & $(0.60,0.30)$ & $(0.70,0.20)$ & $(0.70,0.20)$ & $(0.50,0.40)$ \\
$a_{2}^{3}$ & $(0.70,0.20)$ & $(0.80,0.10)$ & $(0.80,0.10)$ & $(0.80,0.10)$ & $(0.60,0.30)$ \\
& $a_{3}$ & $(0.70,0.20)$ & $(0.70,0.20)$ & $(0.60,0.30)$ & $(0.80,0.10)$ & $(0.70,0.20)$ \\
\cline { 2 - 7 } & $a_{1}$ & $(0.60,0.30)$ & $(0.50,0.40)$ & $(0.70,0.20)$ & $(0.80,0.10)$ & $(0.50,0.40)$ \\
& $a_{2}$ & $(0.60,0.30)$ & $(0.80,0.10)$ & $(0.70,0.20)$ & $(0.80,0.10)$ & $(0.70,0.20)$ \\
& $a_{3}$ & $(0.50,0.40)$ & $(0.80,0.10)$ & $(0.80,0.10)$ & $(0.60,0.30)$ & $(0.60,0.30)$ \\
\cline { 2 - 7 } & $\mathcal{W}$ & 0.144 & 0.219 & 0.210 & 0.305 & 0.122 \\
\hline
\end{tabular}

According to Table 3 and Equation (5), we obtain Table 4:

Table 4. Aggregated IF-multi-attribute information table.

\begin{tabular}{cccccc}
\hline & $\boldsymbol{A}_{\mathbf{1}}$ & $\boldsymbol{A}_{\mathbf{2}}$ & $\boldsymbol{A}_{\mathbf{3}}$ & $\boldsymbol{A}_{\mathbf{4}}$ & $\boldsymbol{A}_{\mathbf{5}}$ \\
\hline$a_{1}$ & $(0.636,0.262)$ & $(0.615,0.282)$ & $(0.638,0.258)$ & $(0.771,0.126)$ & $(0.500,0.400)$ \\
$a_{2}$ & $(0.673,0.226)$ & $(0.800,0.100)$ & $(0.774,0.123)$ & $(0.800,0.100)$ & $(0.716,0.177)$ \\
$a_{3}$ & $(0.699,0.191)$ & $(0.705,0.188)$ & $(0.708,0.186)$ & $(0.714,0.180)$ & $(0.673,0.226)$ \\
$\mathcal{W}$ & 0.144 & 0.219 & 0.210 & 0.305 & 0.122 \\
\hline
\end{tabular}

Then we can obtain the following result using Table 4 and Equation (6):

$$
X=\left\{\left\langle a_{1}, 0.668,0.224\right\rangle,\left\langle a_{2}, 0.770,0.126\right\rangle,\left\langle a_{3}, 0.704,0.190\right\rangle\right\} .
$$

In other words, objective IFS of the "good scheme" $X$ is calculated. In particular, the evaluation value of the scheme needs to be normalized if the attribute types are different [7].

\subsection{DTRIFS Based on an Outranking Relation}

Definition 6. The outranking relation $S$ is determined via the ELECTRE-I method [38], the IFELECTRE-I method [39], IF-multi-attribute information table and the score function, an outranked set is defined as follows:

$$
\forall a \in U,[a]_{S}=\{b \mid a S b \wedge b \in U\}
$$

Proposition 3. Based on the given IF-multi-attribute information table, for $a_{i} \in U$, there exists $a_{t} \in U$, if $A_{i j} \succ A_{t j}, A_{j} \in C$, then we have

$$
a_{t} \in\left[a_{i}\right]_{S}
$$

Proposition 4. If $S_{A_{i j}} \geq S_{A_{t j}}$, then $A_{i j} \succeq A_{t j}$.

Proof. Obviously, it can be proved directly by score function.

Then, we illustrate this in Example 3. 
Example 3. By means of Definitions 3, 4 and the ELECTRE-I method, we stipulate $\delta=0.6$ and $p=0.2$. Based on Definition 6, we obtain the outranked set as follows:

$$
\begin{aligned}
& {\left[a_{1}\right]_{S}=\left\{a_{1}\right\},} \\
& {\left[a_{2}\right]_{S}=\left\{a_{1}, a_{2}, a_{3}\right\},} \\
& {\left[a_{3}\right]_{S}=\left\{a_{1}, a_{3}\right\} .}
\end{aligned}
$$

3.3. Objective Conditional Probability $P\left(X \mid[a]_{S}\right)$ Based on IF Environments

Definition 7. The conditional probability determined by an outranked set and an IFS is defined as follows:

$$
P\left(X \mid[a]_{S}\right)=\frac{\bigoplus_{b \in[a]_{S}} X(b)}{\left|[a]_{S}\right|} .
$$

By virtue of Definition 5, we have:

$$
P\left(\neg X \mid[a]_{S}\right)=(1,0) \ominus P\left(X \mid[a]_{S}\right) .
$$

Proposition 5. $P\left(X \mid[a]_{S}\right)$ and $P\left(\neg X \mid[a]_{S}\right)$ meet the following condition:

$$
P\left(X \mid[a]_{S}\right) \oplus P\left(\neg X \mid[a]_{S}\right)=(1,0) .
$$

Proof. For any $a \in U$, we have

$$
\begin{aligned}
& P\left(X \mid[a]_{S}\right) \oplus P\left(\neg X \mid[a]_{S}\right) \\
& =\frac{\oplus_{b \in[a]_{S}} X(b)}{\left|[a]_{S}\right|} \oplus \frac{\oplus_{b \in[a]_{S}} \neg X(b)}{\left|[a]_{S}\right|} \\
& =\frac{\oplus_{b \in[a]_{S}}(X(b) \oplus \neg X(b))}{\left|[a]_{S}\right|} \\
& =\frac{(1,0)}{\left|[a]_{S}\right|} \\
& =(1,0) .
\end{aligned}
$$

Remark 1. (1) The aforementioned conditional probability is an IFV which is compared with the common one(a real value). This is obviously an extension.

(2) IF $X$ is a fuzzy set, based on IF environment $P\left(X \mid[a]_{S}\right)$ degenerates into the case under fuzzy environment [7]. Similarly, the conditional probability, a form put forward by Yao, is a degenerate form [40].

Example 4. By analyzing Example 3, the conditional probability is determined according to the above method.

To illustrate the above process, we use the alternative $a_{3}$ as a demonstration.

$$
P\left(X \mid\left[a_{3}\right]_{S}\right)=\frac{\sum_{b \in\left[a_{3}\right]_{S}} X(b)}{\left|\left[a_{3}\right]_{S}\right|}=\frac{X\left(a_{1}\right) \oplus X\left(a_{3}\right)}{2}=(0.687,0.206) .
$$

\subsection{WD Methods Based on IF-MADMLFT}

Then, we will present a hybrid information table composed of IF multi-attribute information table and loss function table.

Definition 8. A new hybrid information table will be defined as IF-MADMLFT $=(M A D M, L F T)$, where the IF-MADM $=(U, C, \mathcal{A}, \mathcal{W})$ is an IF multi-attribute information table, $\mathcal{A} \in I F S s, L F T=$ 
$\left(U, \chi_{\triangleleft \triangleright)}\right)$ is a loss function table, $\chi_{\triangleleft \triangleright} \in$ IFSs, $\star$ means the weight of loss function is not taken into account. IF-MADMLFT is shown in Table 5:

Table 5. The IF-MADMLFT information table.

\begin{tabular}{ccccccccccc}
\hline $\boldsymbol{U}$ & $\boldsymbol{A}_{\mathbf{1}}$ & $\boldsymbol{A}_{\mathbf{2}}$ & $\cdots$ & $\boldsymbol{A}_{\boldsymbol{m}}$ & $\chi_{\boldsymbol{P P}}$ & $\chi_{\boldsymbol{B P}}$ & $\chi_{\boldsymbol{N P}}$ & $\chi_{N N}$ & $\chi_{\boldsymbol{B N}}$ & $\chi_{\boldsymbol{P N}}$ \\
\hline$a_{1}$ & $\alpha_{11}^{1}, \ldots, \alpha_{11}^{k}$ & $\alpha_{12}^{1}, \ldots, \alpha_{12}^{k}$ & $\ldots$ & $\alpha_{1 m}^{1}, \ldots, \alpha_{1 m}^{k}$ & $\chi_{P P}\left(a_{1}\right)$ & $\chi_{B P}\left(a_{1}\right)$ & $\chi_{N P}\left(a_{1}\right)$ & $\chi_{N N}\left(a_{1}\right)$ & $\chi_{B N}\left(a_{1}\right)$ & $\chi_{P N}\left(a_{1}\right)$ \\
$a_{2}$ & $\alpha_{21}^{1}, \ldots, \alpha_{21}^{k}$ & $\alpha_{22}^{1}, \ldots, \alpha_{22}^{k}$ & $\ldots$ & $\alpha_{2 m}^{1}, \ldots, \alpha_{2 m}^{k}$ & $\chi_{P P}\left(a_{2}\right)$ & $\chi_{B P}\left(a_{2}\right)$ & $\chi_{N P}\left(a_{2}\right)$ & $\chi_{N N}\left(a_{2}\right)$ & $\chi_{B N}\left(a_{2}\right)$ & $\chi_{P N}\left(a_{2}\right)$ \\
$\vdots$ & $\vdots$ & $\vdots$ & $\ldots$ & $\vdots$ & $\vdots$ & $\vdots$ & $\vdots$ & $\vdots$ & $\vdots$ & $\vdots$ \\
$a_{n}$ & $\alpha_{n 1}^{1}, \ldots, \alpha_{n 1}^{k}$ & $\alpha_{n 2}^{1}, \ldots, \alpha_{n 2}^{k}$ & $\ldots$ & $\alpha_{n m}^{1}, \ldots, \alpha_{n m}^{k}$ & $\chi_{P P}\left(a_{n}\right)$ & $\chi_{B P}\left(a_{n}\right)$ & $\chi_{N P}\left(a_{n}\right)$ & $\chi_{N N}\left(a_{n}\right)$ & $\chi_{B N}\left(a_{n}\right)$ & $\chi_{P N}\left(a_{n}\right)$ \\
\hline $\mathcal{W}$ & $\omega_{1}$ & $\omega_{2}$ & $\ldots$ & $\omega_{m}$ & $\star$ & $\star$ & $\star$ & $\star$ & $\star$ & $\star$ \\
\hline
\end{tabular}

From the hybrid information table, we can get that for each the value of $a_{i}$ which can be expressed as $n+6$ vectors:

$$
\mathbb{F}\left(a_{i}\right)=\left(A_{i 1}, A_{i 2}, \ldots, A_{i m}, \chi_{P P}\left(a_{i}\right), \chi_{B P}\left(a_{i}\right), \chi_{N P}\left(a_{i}\right), \chi_{N N}\left(a_{i}\right), \chi_{B N}\left(a_{i}\right), \chi_{P N}\left(a_{i}\right)\right),
$$

where $A_{i j}$ is obtained by using $\alpha_{i j}^{1}, \ldots, \alpha_{i j}^{k}$ from the Equation (5).

For any $a_{i}(i=1,2, \ldots, n)$, by means of the realistic explanation of the loss functions, we have:

$$
\chi_{N P}\left(a_{i}\right) \succ \chi_{B P}\left(a_{i}\right) \succeq \chi_{P P}\left(a_{i}\right) ; \chi_{P N}\left(a_{i}\right) \succ \chi_{B N}\left(a_{i}\right) \succeq \chi_{N N}\left(a_{i}\right) .
$$

The IF-expected losses $R\left(a_{\bowtie} \mid[a]_{S}\right)(\bowtie=P, B, N)$ of taking three actions are calculated as follows:

$$
\begin{aligned}
& R\left(a_{P} \mid[a]_{S}\right)=\left(\chi_{P P} \otimes P\left(X \mid[a]_{S}\right)\right) \oplus\left(\chi_{P N} \otimes P\left(\neg X \mid[a]_{S}\right)\right), \\
& R\left(a_{B} \mid[a]_{S}\right)=\left(\chi_{B P} \otimes P\left(X \mid[a]_{S}\right)\right) \oplus\left(\chi_{B N} \otimes P\left(\neg X \mid[a]_{S}\right)\right), \\
& R\left(a_{N} \mid[a]_{S}\right)=\left(\chi_{N P} \otimes P\left(X \mid[a]_{S}\right)\right) \oplus\left(\chi_{N N} \otimes P\left(\neg X \mid[a]_{S}\right)\right) .
\end{aligned}
$$

In light of Bayesian minimum-risk criterion, we have:

$\left(P_{I}\right)$ If $R\left(a_{P} \mid[a]_{S}\right) \prec R\left(a_{B} \mid[a]_{S}\right)$ and $R\left(a_{P} \mid[a]_{S}\right) \prec R\left(a_{N} \mid[a]_{S}\right)$, then $a \in \operatorname{POS}(X)$,

$\left(B_{I}\right)$ If $R\left(a_{B} \mid[a]_{S}\right) \preceq R\left(a_{P} \mid[a]_{S}\right)$ and $R\left(a_{B} \mid[a]_{S}\right) \preceq R\left(a_{N} \mid[a]_{S}\right)$, then $a \in B N D(X)$,

$\left(N_{I}\right)$ If $R\left(a_{N} \mid[a]_{S}\right) \prec R\left(a_{P} \mid[a]_{S}\right)$ and $R\left(a_{N} \mid[a]_{S}\right) \prec R\left(a_{B} \mid[a]_{S}\right)$, then $a \in N E G(X)$.

By virtue of the definition of score functions, we have:

$$
\begin{aligned}
& \left(P_{I}\right) \text { If } S_{R\left(a_{P} \mid[a]_{S}\right)}<S_{R\left(a_{B} \mid[a]_{S}\right)} \text { and } S_{R\left(a_{P} \mid[a]_{S}\right)}<S_{R\left(a_{N} \mid[a]_{S}\right),} a \in \operatorname{POS}(X), \\
& \left(B_{I}\right) \text { If } S_{R\left(a_{B} \mid[a]_{S}\right)} \leq S_{R\left(a_{P} \mid[a]_{S}\right)} \text { and } S_{R\left(a_{B} \mid[a]_{S}\right)} \leq S_{R\left(a_{N} \mid[a]_{S}\right),} a \in \operatorname{BND}(X), \\
& \left(N_{I}\right) \text { If } S_{R\left(a_{N} \mid[a]_{S}\right)}<S_{R\left(a_{P} \mid[a]_{S}\right)} \text { and } S_{R\left(a_{N} \mid[a]_{S}\right)}<S_{R\left(a_{B} \mid[a]_{S}\right)}, a \in N E G(X) .
\end{aligned}
$$

\subsection{Decision Making Methods under IF-DTRSs}

In decision making problems, the ranking of alternatives is undoubtedly the most important aspect that helps the decision maker to select the optimal solution. We first divide all the alternatives into three regions, then according to a DM's preferences for the rules $\left(P_{I}\right)-\left(N_{I}\right)$, we can obtain the order of all alternatives:

$$
\left(P_{I}\right) \succ\left(B_{I}\right) \succ\left(N_{I}\right)
$$

\section{Application of the Novel 3WD Method to IF-MADMLFT}

We plan to study the new 3WD IF-DTRS model aiming to solve the practical IF-MADM problem in this chapter. 


\subsection{The Description of the Problem}

Many traditional MADM methods have solved the classical problem of supplier selection. However, these existing methods often neglect one point, that is, the actual decision-making process needs more information and evaluation; because of this, these methods are easy to lead to too harsh decision-making results, which may not maximize the interests of the enterprise. It is very often for enterprises to inspect or evaluate suppliers further so as to decrease potential risks or losses. Therefore, adding further investigation as another way to the decision results is necessary which is able to make the decision-making process more careful, rigorous and is better as well as more comprehensive to inspect suppliers. Then, we will illustrate the new 3WD model proposed in this paper with an example of the supplier selection.

Suppose that $U=\left\{a_{1}, a_{2}, \ldots, a_{n}\right\}$ can be seen as a set of component suppliers. $C=\left\{A_{1}, A_{2}, \ldots, A_{m}\right\}$ is a set consisted of $\mathrm{m}$ different index evaluation aspects and $E=\left\{E_{1}, E_{2}, \ldots, E_{k}\right\}$ is a set of $\mathrm{k}$ heads of departments.

Let $\mathcal{A}=\left\{A_{i j} \in I F S s \mid a_{i} \in U, A_{j} \in C ; i=1,2, \ldots, n ; j=1,2, \ldots, m ; l=1,2, \ldots, k\right\}$ denote the evaluation set of the alternative $a_{i}$ under the attribute $A_{j}$ with the lth expert. Let $\omega_{j}, \tau_{l} \in(0,1)(j=1,2, \ldots, m ; l=1,2, \ldots, k)$ denote the weights of the attributes $A_{j}$ and the experts $E_{l}$ satisfying $\sum_{j=1}^{m} \omega_{j}=1$ and $\sum_{l=1}^{k} \tau_{l}=1$, respectively. Nowadays, let $\mathcal{W}=\left\{\omega_{1}, \omega_{2}, \ldots, \omega_{m}\right\}$ represent weight vector of every attribute. Here, we call $(U, C, E, \mathcal{A}, \mathcal{W})$ an IF MADM matrix for the supplier selection. The problem for enterprises is to decide an optimal supplier from all suppliers of product components. The heads of departments evaluate all suppliers of product components based on previous experiences and determines a comprehensive evaluation set $X$. In general, the intuitionistic fuzzy set $X$ represents a concept of "good supplier". We express the final conclusion as the optimal suppliers of product components, excluding selecting suppliers and the supplier that need additional evaluation and inspecting. In other words, in light of $(\mathrm{U}, \mathrm{C}, \mathrm{E}, \mathcal{A}, \mathcal{W})$, supplier selection problem can be divided into three region, namely $\operatorname{POS}(X), B N D(X)$ and $N E G(X)$.

Assume that $\chi_{P P}\left(a_{i}\right), \chi_{B P}\left(a_{i}\right)$ and $\chi_{N P}\left(a_{i}\right)$ are the loss functions for taking the actions $a_{P}, a_{B}$ and $a_{N}$ when a supplier $a_{i}$ is considered to be a good supplier, whereas $\chi_{P N}\left(a_{i}\right)$, $\chi_{B N}\left(a_{i}\right)$ and $\chi_{N N}\left(a_{i}\right)$ are the loss functions for taking the actions $a_{P}, a_{B}$ and $a_{N}$ when a supplier $a_{i}$ is considered to be a bad supplier.

\subsection{An Application of the 3WD Method under IF Environments}

For each supplier $a_{i}$, the evaluation value in the IF-MADMLFT which can be expressed as $n+6$ vectors:

$$
\mathbb{F}\left(a_{i}\right)=\left(A_{i 1}, A_{i 2}, \ldots, A_{i m}, \chi_{P P}\left(a_{i}\right), \chi_{B P}\left(a_{i}\right), \chi_{N P}\left(a_{i}\right), \chi_{N N}\left(a_{i}\right), \chi_{B N}\left(a_{i}\right), \chi_{P N}\left(a_{i}\right)\right),
$$

where $A_{i j}$ is obtained by using $A_{i j}^{1}, \ldots, A_{i j}^{k}$ from the Equation (5) and $\chi_{P P}\left(a_{i}\right), \chi_{B P}\left(a_{i}\right)$, $\chi_{N P}\left(a_{i}\right), \chi_{N N}\left(a_{i}\right), \chi_{B N}\left(a_{i}\right), \chi_{P N}\left(a_{i}\right)$ are the corresponding loss functions of $a_{i}$.

In order to ensure the correctness of the decision, we need to normalize the IF multiattribute information table. Suppose $I_{1}$ and $I_{2}$ are benefit attribute set and cost attribute set, respectively.

If $j \in I_{1}$, we have

$$
B_{i j}=A_{i j} \oslash \max _{1 \leq i \leq n} A_{i j}
$$

If $j \in I_{2}$, we have

$$
B_{i j}=\min _{1 \leq i \leq n} A_{i j} \oslash A_{i j}
$$

where $B_{i j}$ aggregated by evaluation values of $\mathrm{k}$ experts is represented by the evaluation value of the supplier $a_{i}$ with respect to $A_{j}$.

First of all we can get the IF-outranked set $[a]_{S}$ for each supplier $a \in U$. Then, according to the evaluation values of suppliers and the weights of attributes, we can obtain 
an objective IFS $X$, which means the concept of "good supplier". Next, we can calculate the conditional probability $P\left(X \mid[a]_{S}\right)$ of the IF-outranked set of the supplier $a$ with respect to the IF concept of the "good supplier" $X$. In addition, each supplier $a$ has corresponding loss functions in relation to three action and two states.

The IF-expected losses $R\left(a_{\bowtie} \mid[a]_{S}\right)(\bowtie=P, B, N)$ of each supplier $a \in U$ are computed as follows:

$$
\begin{aligned}
R\left(a_{P} \mid[a]_{S}\right) & =\left(\chi_{P P}^{a} \otimes P\left(X \mid[a]_{S}\right)\right) \oplus\left(\chi_{P N}^{a} \otimes P\left(\neg X \mid[a]_{S}\right)\right), \\
R\left(a_{B} \mid[a]_{S}\right) & =\left(\chi_{B P}^{a} \otimes P\left(X \mid[a]_{S}\right)\right) \oplus\left(\chi_{B N}^{a} \otimes P\left(\neg X \mid[a]_{S}\right)\right), \\
R\left(a_{N} \mid[a]_{S}\right) & =\left(\chi_{N P}^{a} \otimes P\left(X \mid[a]_{S}\right)\right) \oplus\left(\chi_{N N}^{a} \otimes P\left(\neg X \mid[a]_{S}\right)\right) .
\end{aligned}
$$

According to Bayesian the minimum-risk decision making rules, we have:

$\left(P_{I}\right)$ If $R\left(a_{P} \mid[a]_{S}\right) \prec R\left(a_{B} \mid[a]_{S}\right)$ and $R\left(a_{P} \mid[a]_{S}\right) \prec R\left(a_{N} \mid[a]_{S}\right)$, then $a \in \operatorname{POS}(X)$,

$\left(B_{I}\right)$ If $R\left(a_{B} \mid[a]_{S}\right) \preceq R\left(a_{P} \mid[a]_{S}\right)$ and $R\left(a_{B} \mid[a]_{S}\right) \preceq R\left(a_{N} \mid[a]_{S}\right)$, then $a \in B N D(X)$,

$\left(N_{I}\right)$ If $R\left(a_{N} \mid[a]_{S}\right) \prec R\left(a_{P} \mid[a]_{S}\right)$ and $R\left(a_{N} \mid[a]_{S}\right) \prec R\left(a_{B} \mid[a]_{S}\right)$, then $a \in N E G(X)$.

In light of three decision rules which can be simplified to Equation (14), the associated loss which is the risk of taking the final decision for a supplier $a$ is defined as follows:

$$
\operatorname{loss}(a)=\min \left\{S_{R\left(a_{P} \mid[a]_{S}\right)}, S_{R\left(a_{B} \mid[a]_{S}\right)}, S_{R\left(a_{N} \mid[a]_{S}\right)}\right\}
$$

The associated loss of supplier $a$ depends on the region of $a$. Namely if $a \in P O S(X)$, finally supplier $a$ is selected and the associated loss is $S_{R\left(a_{P} \mid[a]_{S}\right)}$.

We can rank all the suppliers $a_{1}, a_{2}, \ldots, a_{n}$ ultimately via two rules as follows:

(1) According to a DM's preferences for the rule $\left(P_{I}\right)-\left(N_{I}\right)$, the priority order of all alternatives is $\left(P_{I}\right) \succ\left(B_{I}\right) \succ\left(N_{I}\right)$, which means that the priority of the suppliers in $\operatorname{POS}(X)$ is greater than the suppliers in $B N D(X)$ and the priority of the suppliers in $B N D(X)$ is greater than suppliers in $N E G(X)$. This type fits our semantic interpretation.

(2) Suppliers in the same domain are ranked in descending order of their respective losses, which is in line with reality.

For example, if $a_{1}, a_{2} \in \operatorname{POS}(X), a_{3} \in B N D(X), a_{4} \in N E G(X)$ and $\operatorname{loss}\left(a_{1}\right)>$ $\operatorname{loss}\left(a_{2}\right)$, then the final order is $a_{2} \succ a_{1} \succ a_{3} \succ a_{4}$.

\subsection{An Algorithm of 3WD-MADM Method}

Algorithm 1 is aim to solve the supplier selection problem in IF environment based on 3WD-MADM method, the algorithm of the above method is summarized as follows:

Input: An IF-MADMLFT $\left(U, C, E, \mathcal{A}, \mathcal{W}, \chi_{\bowtie}\right)$.

Output: The sorting of all suppliers and the optimal suppliers.

Step 1: Aggregate the IF-MADMLFT by Equation (5).

Step 2: Standardize the IF-MADMLFT by Equations (15) and (16).

Step 3: The IF-outranked set $[a]_{S}$ of each supplier $a$ is acquired via Definition 6.

Step 4: The concept of the IFS $X$ is determined in accordance with $\left(U, C, E, \mathcal{A}, \mathcal{W}, \chi_{\bowtie}\right)$.

Step 5: Compute the conditional probability $P\left(X \mid[a]_{S}\right)$ and $P\left(\neg X \mid[a]_{S}\right)$.

Step 6: Calculate the expected loss function $R\left(a_{\bowtie} \mid[a]_{S}\right)(\bowtie=P, B, N)$ of each supplier $a$ via Equation (17).

Step 7: Determine that each supplier $a$ is eventually selected, or not selected, or requires further investigation using the decision rules.

Step 8: The corresponding loss value of each supplier is computed by Equation (19).

Step 9: Use the two rules (1)-(2) to rank all suppliers. 


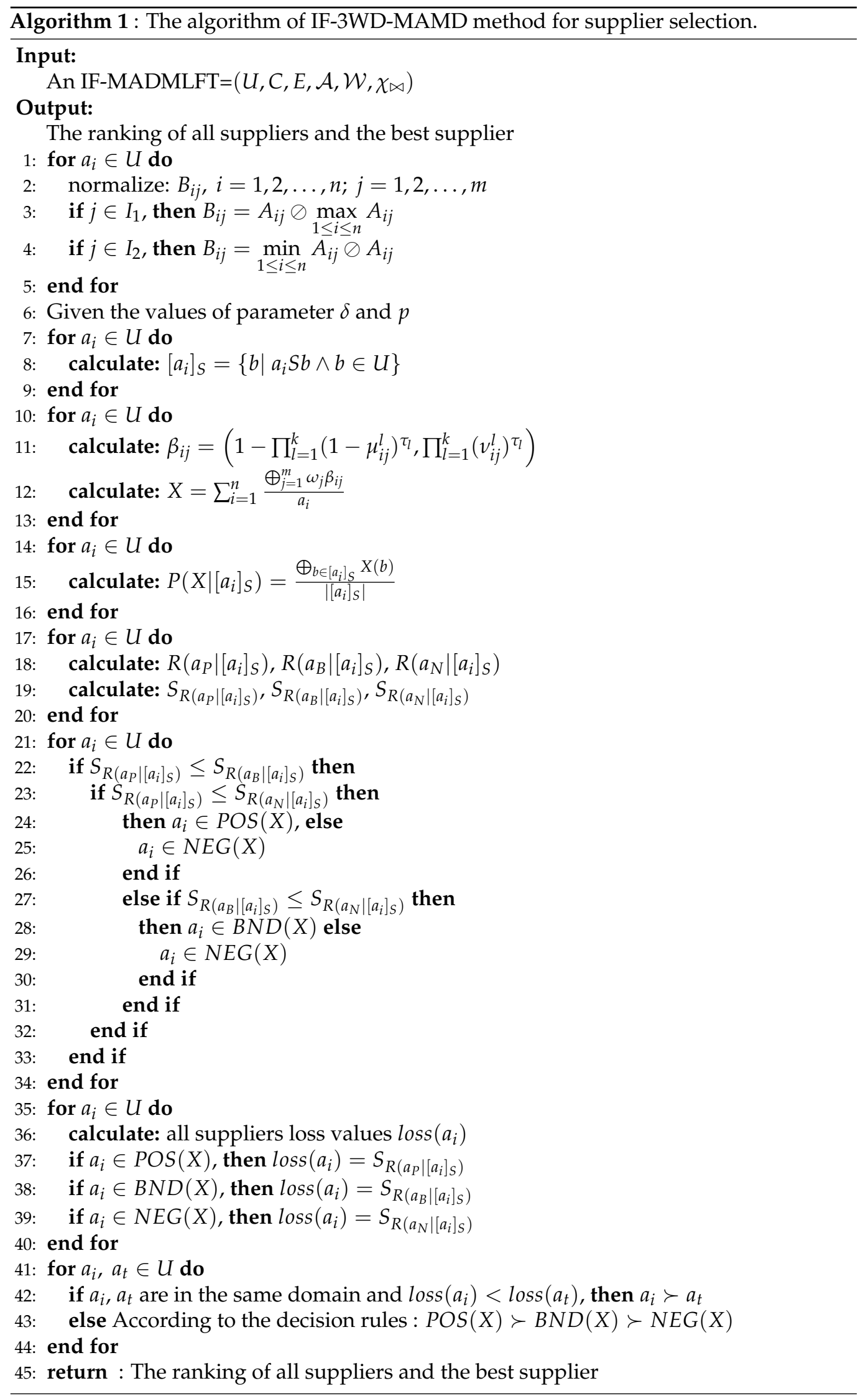

\section{Illustrative Examples}

We use an example to show that the new IF 3WD is reasonable. 


\subsection{Numerical Example and Analysis}

In order to prove the effectiveness of the novel IF-3WD method and the algorithm, we will study a realistic IF MADM example of supplier selection.

Ten component suppliers can be considered as a set of alternatives $U=\left\{a_{1}, a_{2}, \ldots, a_{10}\right\}$ when a core manufacturing enterprise to select suppliers of product components. The manufacturer established relevant index evaluation system according to previous experience with four criteria which are technical level $\left(A_{1}\right)$, service level $\left(A_{2}\right)$, business ability $\left(A_{3}\right)$ and enterprise environment $\left(A_{4}\right)$. The weights are calculated, respectively, $0.22,0.22,0.36$ and 0.2 . Leaders from different departments have been gathered by manufacturer to evaluate ten suppliers on the basis of the developed index evaluation system. These estimates have been summarized and analyzed at present, hence, step 1 has been completed. A supplier has two states: a good supplier or a bad supplier. In real life, for the benefit of the enterprise, the enterprise should collect more information to decide which suppliers to choose and which not to choose, and further consider which suppliers. Therefore, the head of the business unit needs to divide the ten potential suppliers into three regions, namely, acceptance $a_{P}$, rejection $a_{N}$ and the indetermination $a_{B}$. The IF-MADMLFT is shown in Table 6 where $\star$ means the weight of loss function is not taken into account and the score function in relation to each attribute's IF evaluation value is expressed in Table 7.

Table 6. The IF-MADMLFT information table of suppliers.

\begin{tabular}{ccccccccccc}
\hline $\boldsymbol{U}$ & $A_{\mathbf{1}}$ & $A_{\mathbf{2}}$ & $A_{\mathbf{3}}$ & $\boldsymbol{A}_{\mathbf{4}}$ & $\chi_{\boldsymbol{P P}}$ & $\chi_{\boldsymbol{B} P}$ & $\chi_{N P}$ & $\chi_{N N}$ & $\chi_{B N}$ & $\chi_{P N}$ \\
\hline$a_{1}$ & $(0.6,0.3)$ & $(0.2,0.4)$ & $(0.3,0.3)$ & $(0.1,0.5)$ & $(0,1)$ & $(0.11,0.74)$ & $(0.33,0.36)$ & $(0,1)$ & $(0.11,0.72)$ & $(0.37,0.25)$ \\
$a_{2}$ & $(0.4,0.5)$ & $(0.7,0.2)$ & $(0.6,0.4)$ & $(0.5,0.3)$ & $(0,1)$ & $(0.19,0.77)$ & $(0.57,0.34)$ & $(0,1)$ & $(0.13,0.84)$ & $(0.37,0.55)$ \\
$a_{3}$ & $(0.5,0.3)$ & $(0.1,0.6)$ & $(0.4,0.2)$ & $(0.3,0.4)$ & $(0,1)$ & $(0.13,0.70)$ & $(0.35,0.32)$ & $(0,1)$ & $(0.09,0.76)$ & $(0.37,0.29)$ \\
$a_{4}$ & $(0.7,0.2)$ & $(0.9,0.1)$ & $(0.3,0.5)$ & $(0.8,0.2)$ & $(0,1)$ & $(0.22,0.72)$ & $(0.72,0.23)$ & $(0,1)$ & $(0.11,0.82)$ & $(0.30,0.58)$ \\
$a_{5}$ & $(0.6,0.1)$ & $(0.6,0.2)$ & $(0.3,0.3)$ & $(0.5,0.2)$ & $(0,1)$ & $(0.15,0.66)$ & $(0.49,0.20)$ & $(0,1)$ & $(0.07,0.79)$ & $(0.21,0.46)$ \\
$a_{6}$ & $(0.1,0.8)$ & $(0.3,0.5)$ & $(0.2,0.4)$ & $(0.5,0.1)$ & $(0,1)$ & $(0.07,0.78)$ & $(0.27,0.37)$ & $(0,1)$ & $(0.18,0.65)$ & $(0.51,0.23)$ \\
$a_{7}$ & $(0.4,0.5)$ & $(0.3,0.6)$ & $(0.4,0.2)$ & $(0.3,0.5)$ & $(0,1)$ & $(0.12,0.74)$ & $(0.36,0.38)$ & $(0,1)$ & $(0.12,0.77)$ & $(0.44,0.35)$ \\
$a_{8}$ & $(0.2,0.6)$ & $(0.6,0.3)$ & $(0.8,0.1)$ & $(0.4,0.2)$ & $(0,1)$ & $(0.24,0.64)$ & $(0.60,0.22)$ & $(0,1)$ & $(0.09,0.83)$ & $(0.30,0.48)$ \\
$a_{9}$ & $(0.3,0.4)$ & $(0.8,0.1)$ & $(0.5,0.4)$ & $(0.6,0.3)$ & $(0,1)$ & $(0.18,0.75)$ & $(0.58,0.28)$ & $(0,1)$ & $(0.12,0.82)$ & $(0.32,0.51)$ \\
$a_{10}$ & $(0.4,0.1)$ & $(0.1,0.3)$ & $(0.3,0.4)$ & $(0.5,0.5)$ & $(0,1)$ & $(0.11,0.71)$ & $(0.33,0.29)$ & $(0,1)$ & $(0.11,0.73)$ & $(0.35,0.28)$ \\
\hline $\mathcal{W}$ & 0.22 & 0.22 & 0.36 & 0.2 & $\star$ & $\star$ & $\star$ & $\star$ & $\star$ & \\
\hline
\end{tabular}

Table 7. The score table of suppliers.

\begin{tabular}{ccccc}
\hline$U$ & $A_{\mathbf{1}}$ & $A_{\mathbf{2}}$ & $A_{\mathbf{3}}$ & $A_{\mathbf{4}}$ \\
\hline$a_{1}$ & 0.3 & -0.2 & 0 & -0.4 \\
$a_{2}$ & -0.1 & 0.5 & 0.2 & 0.2 \\
$a_{3}$ & 0.2 & -0.5 & 0.2 & -0.1 \\
$a_{4}$ & 0.5 & 0.8 & -0.2 & 0.6 \\
$a_{5}$ & 0.5 & 0.4 & 0 & 0.3 \\
$a_{6}$ & -0.7 & -0.2 & -0.2 & 0.4 \\
$a_{7}$ & -0.1 & -0.3 & 0.2 & -0.2 \\
$a_{8}$ & -0.4 & 0.3 & 0.7 & 0.2 \\
$a_{9}$ & -0.1 & 0.7 & 0.1 & 0.3 \\
$a_{10}$ & 0.3 & -0.2 & -0.1 & 0 \\
\hline
\end{tabular}

\subsection{Description of the Proposed Method}

Next, we use the algorithm presented in Section 4.3 to process the supplier selection case described in Section 5.1. The steps are shown below:

In Step 1, these evaluation values have been aggregated and analyzed, so Step 1 has been completed. 
In Step 2, since all four attributes are all benefit attributes, this step has been accomplished.

In Step 3, the IF-outranked set $\left[a_{i}\right]_{S}(i=1,2, \ldots, 10)$ of each supplier $a_{i} \in U$ is acquired by virtue of Definition 6 and the ELECTRE-I method $(\delta=0.6, p=0.2)$.

In light of Table 7, we have

$$
\begin{array}{ll}
{\left[a_{1}\right]_{S}=\left\{a_{1}\right\},} & {\left[a_{6}\right]_{S}=\left\{a_{6}\right\},} \\
{\left[a_{2}\right]_{S}=\left\{a_{2}, a_{6}, a_{7}\right\},} & {\left[a_{7}\right]_{S}=\left\{a_{7}\right\},} \\
{\left[a_{3}\right]_{S}=\left\{a_{3}, a_{7}\right\},} & {\left[a_{8}\right]_{S}=\left\{a_{6}, a_{8}\right\},} \\
{\left[a_{4}\right]_{S}=\left\{a_{1}, a_{4}, a_{5}, a_{6}, a_{10}\right\},} & {\left[a_{9}\right]_{S}=\left\{a_{2}, a_{6}, a_{7}, a_{9}\right\},} \\
{\left[a_{5}\right]_{S}=\left\{a_{1}, a_{3}, a_{5}, a_{6}, a_{7}, a_{10}\right\},} & {\left[a_{10}\right]_{S}=\left\{a_{10}\right\} .}
\end{array}
$$

In Step 4, the evaluation values of Table 6 are integrated by an IFWA operator to obtain $X$ which shows the concept of the "good supplier".

Taking the supplier $a_{3}$ as an example, we can calculate it as follows:

$$
\begin{aligned}
& \omega_{1} A_{1}\left(a_{3}\right) \oplus \omega_{2} A_{2}\left(a_{3}\right) \oplus \omega_{3} A_{3}\left(a_{3}\right) \oplus \omega_{4} A_{4}\left(a_{3}\right) \\
& =0.22(0.5,0.3) \oplus 0.22(0.1,0.6) \oplus 0.36(0.4,0.2) \oplus 0.2(0.3,0.4) \\
& =(0.350,0.320) .
\end{aligned}
$$

By virtue of aggregations, we can obtain the IFS $X$ below:

$$
\begin{aligned}
X= & \left\{\left\langle a_{1}, 0.330,0.354\right\rangle,\left\langle a_{2}, 0.571,0.341\right\rangle,\left\langle a_{3}, 0.350,0.320\right\rangle,\left\langle a_{4}, 0.705,0.239\right\rangle,\left\langle a_{5}, 0.488,0.199\right\rangle,\right. \\
& \left.\left\langle a_{6}, 0.274,0.371\right\rangle,\left\langle a_{7}, 0.360,0.374\right\rangle,\left\langle a_{8}, 0.606,0.217\right\rangle,\left\langle a_{9}, 0.579,0.278\right\rangle,\left\langle a_{10}, 0.331,0.289\right\rangle\right\} .
\end{aligned}
$$

In Step 5, the conditional probability of the IF-outranked set of each supplier with respect to the IF concept of the "good supplier" is calculate as follows:

$$
\begin{aligned}
& P\left(X \mid\left[a_{1}\right]_{S}\right)=\frac{\sum_{b \in\left[a_{1}\right]_{S}} X(b)}{\left|\left[a_{1}\right]_{S}\right|}=(0.330,0.354), \\
& P\left(X \mid\left[a_{6}\right]_{S}\right)=\frac{\sum_{b \in\left[a_{6}\right]_{S}} X(b)}{\left|\left[a_{6}\right]_{S}\right|}=(0.274,0.371), \\
& P\left(X \mid\left[a_{2}\right]_{S}\right)=\frac{\sum_{b \in\left[a_{2}\right]_{S} X(b)}}{\left|\left[a_{2}\right]_{S}\right|}=(0.416,0.362), \\
& P\left(X \mid\left[a_{7}\right]_{S}\right)=\frac{\sum_{b \in\left[a_{7}\right]_{S}} X(b)}{\left|\left[a_{7}\right]_{S}\right|}=(0.360,0.374), \\
& P\left(X \mid\left[a_{3}\right]_{S}\right)=\frac{\sum_{b \in\left[a_{3}\right]_{S}} X(b)}{\left|\left[a_{3}\right]_{S}\right|}=(0.355,0.346), \\
& P\left(X \mid\left[a_{8}\right]_{S}\right)=\frac{\sum_{b \in\left[a_{8}\right]_{S}} X(b)}{\left|\left[a_{8}\right]_{S}\right|}=(0.465,0.284), \\
& P\left(X \mid\left[a_{4}\right]_{S}\right)=\frac{\sum_{b \in\left[a_{4}\right]_{S} X(b)}}{\left|\left[a_{4}\right]_{S}\right|}=(0.453,0.283), \\
& P\left(X \mid\left[a_{9}\right]_{S}\right)=\frac{\sum_{b \in\left[a_{9}\right]_{S}} X(b)}{\left|\left[a_{9}\right]_{S}\right|}=(0.462,0.339), \\
& P\left(X \mid\left[a_{5}\right]_{S}\right)=\frac{\sum_{b \in\left[a_{5}\right]_{S}} X(b)}{\left|\left[a_{5}\right]_{S}\right|}=(0.359,0.311), \\
& P\left(X \mid\left[a_{10}\right]_{S}\right)=\frac{\sum_{b \in\left[a_{10}\right]_{S}} X(b)}{\left|\left[a_{10}\right]_{S}\right|}=(0.331,0.289) .
\end{aligned}
$$

We can compute the conditional probability $P\left(\neg X \mid\left[a_{i}\right]_{S}\right)(i=1,2, \ldots, 10)$ of each supplier according to Proposition 5:

$$
P\left(\neg X \mid\left[a_{3}\right]_{S}\right)=(1,0) \ominus P\left(X \mid\left[a_{3}\right]_{S}\right)=(1,0) \ominus(0.355,0.346)=(1,0) .
$$

In Step 6, by virtue of Equation (17), the expected loss function $R\left(a_{\bowtie} \mid[a]_{S}\right)(\bowtie=P, B, N)$ of each supplier $a$ is computed. Take the supplier $a_{3}$, for example:

$$
\begin{aligned}
R\left(a_{P} \mid\left[a_{3}\right]_{S}\right) & =\left(\chi_{P P}^{a_{3}} \otimes P\left(X \mid\left[a_{3}\right]_{S}\right)\right) \oplus\left(\chi_{P N}^{a_{3}} \otimes P\left(\neg X \mid\left[a_{3}\right]_{S}\right)\right) \\
& =((0,1) \otimes(0.355,0.346)) \oplus((0.37,0.29) \otimes(1,0)) \\
& =(0.37,0.29) .
\end{aligned}
$$




$$
\begin{aligned}
R\left(a_{B} \mid\left[a_{3}\right]_{S}\right)= & \left(\chi_{B P}^{a_{3}} \otimes P\left(X \mid\left[a_{3}\right]_{S}\right)\right) \oplus\left(\chi_{B N}^{a_{3}} \otimes P\left(\neg X \mid\left[a_{3}\right]_{S}\right)\right) \\
= & ((0.13,0.70) \otimes(0.355,0.346)) \oplus((0.09,0.76) \otimes(1,0)) \\
= & (0.1320,0.6109) . \\
R\left(a_{N} \mid\left[a_{3}\right]_{S}\right) & =\left(\chi_{N P}^{a_{3}} \otimes P\left(X \mid\left[a_{3}\right]_{S}\right)\right) \oplus\left(\chi_{N N}^{a_{3}} \otimes P\left(\neg X \mid\left[a_{3}\right]_{S}\right)\right) \\
& =((0.35,0.32) \otimes(0.355,0.346)) \oplus((0,1) \otimes(1,0)) \\
& =(0.1242,0.5553) .
\end{aligned}
$$

The expected loss values of all suppliers are shown in Table 8.

Table 8. The expected losses of suppliers.

\begin{tabular}{lccc}
\hline $\boldsymbol{U}$ & $\boldsymbol{R}\left(\boldsymbol{a}_{\boldsymbol{P}} \mid\left[\boldsymbol{a}_{i}\right]_{S}\right)$ & $\boldsymbol{R}\left(\boldsymbol{a}_{\boldsymbol{B}} \mid\left[\boldsymbol{a}_{\boldsymbol{i}}\right]_{S}\right)$ & $\boldsymbol{R}\left(\boldsymbol{a}_{\boldsymbol{N}} \mid\left[\boldsymbol{a}_{\boldsymbol{i}}\right]_{S}\right)$ \\
\hline$a_{1}$ & $(0.37,0.25)$ & $(0.1423,0.5990)$ & $(0.1089,0.5866)$ \\
$a_{2}$ & $(0.37,0.55)$ & $(0.1987,0.7168)$ & $(0.2371,0.5789)$ \\
$a_{3}$ & $(0.37,0.29)$ & $(0.1320,0.6109)$ & $(0.1242,0.5553)$ \\
$a_{4}$ & $(0.30,0.58)$ & $(0.1987,0.6553)$ & $(0.3262,0.4479)$ \\
$a_{5}$ & $(0.21,0.46)$ & $(0.1200,0.6049)$ & $(0.1759,0.4488)$ \\
$a_{6}$ & $(0.51,0.23)$ & $(0.1957,0.5600)$ & $(0.0740,0.6037)$ \\
$a_{7}$ & $(0.44,0.35)$ & $(0.1580,0.6446)$ & $(0.1296,0.6119)$ \\
$a_{8}$ & $(0.30,0.48)$ & $(0.1916,0.6160)$ & $(0.2790,0.4415)$ \\
$a_{9}$ & $(0.32,0.51)$ & $(0.1932,0.6845)$ & $(0.2680,0.5241)$ \\
$a_{10}$ & $(0.35,0.28)$ & $(0.1424,0.5795)$ & $(0.1092,0.4952)$ \\
\hline
\end{tabular}

In Step 7, we calculate the scores $S_{R\left(a_{\bowtie} \mid[a]_{S}\right)}(\bowtie=P, B, N)$, as shown in Table 9.

Table 9. The $S_{R\left(a_{\bowtie} \mid[a]_{s}\right)}$ values of suppliers $(\bowtie=P, B, N)$.

\begin{tabular}{cccc}
\hline$U$ & $S_{R\left(a_{P} \mid\left[a_{i}\right]_{s}\right)}$ & $S_{R\left(a_{B} \mid\left[a_{i}\right]_{s}\right)}$ & $S_{R\left(a_{N} \mid\left[a_{i}\right]_{S}\right)}$ \\
\hline$a_{1}$ & 0.12 & -0.4567 & -0.4777 \\
$a_{2}$ & -0.18 & -0.5181 & -0.3418 \\
$a_{3}$ & 0.08 & -0.4789 & -0.4311 \\
$a_{4}$ & -0.28 & -0.4566 & -0.1217 \\
$a_{5}$ & -0.25 & -0.4849 & -0.2729 \\
$a_{6}$ & 0.28 & -0.3643 & -0.5297 \\
$a_{7}$ & 0.09 & -0.4866 & -0.4823 \\
$a_{8}$ & -0.18 & -0.4244 & -0.1625 \\
$a_{9}$ & -0.19 & -0.4913 & -0.2561 \\
$a_{10}$ & 0.07 & -0.4371 & -0.3860 \\
\hline
\end{tabular}

By virtue of Equation (17) and the score function, we calculate each supplier $a^{\prime}$ s expected losses shown in Table 8 and $S_{R\left(a_{\bowtie} \mid[a]_{S}\right)}(\bowtie=P, B, N)$ shown in Table 9. These two are under the three actions.

According to the decision rules $\left(P_{I}\right)-\left(N_{I}\right)$ and Equation (19), we compute the associated loss of each supplier $a_{i} \in U(i=1,2, \ldots, 10)$ which shown in Table 10. 
Table 10. Decision rules and associated loss of suppliers.

\begin{tabular}{lcc}
\hline $\boldsymbol{U}$ & Decision Actions & Associated Loss $\left(a_{\boldsymbol{i}}\right)$ \\
\hline$a_{1}$ & $N_{I}$ & -0.4777 \\
$a_{2}$ & $B_{I}$ & -0.5181 \\
$a_{3}$ & $B_{I}$ & -0.4789 \\
$a_{4}$ & $B_{I}$ & -0.4566 \\
$a_{5}$ & $B_{I}$ & -0.4849 \\
$a_{6}$ & $N_{I}$ & -0.5297 \\
$a_{7}$ & $B_{I}$ & -0.4866 \\
$a_{8}$ & $B_{I}$ & -0.4244 \\
$a_{9}$ & $B_{I}$ & -0.4913 \\
$a_{10}$ & $B_{I}$ & -0.4371 \\
\hline
\end{tabular}

We have the following conclusions via the decision rules $\left(P_{I}\right)-\left(N_{I}\right): \operatorname{POS}(X)=\varnothing$, $B N D(X)=\left\{a_{2}, a_{3}, a_{4}, a_{5}, a_{7}, a_{8}, a_{9}, a_{10}\right\}, N E G(X)=\left\{a_{1}, a_{6}\right\}$. Therefore, the corresponding results are described below: no supplier is the optimal one, $a_{1}, a_{6}$ are not recommended and $a_{2}, a_{3}, a_{4}, a_{5}, a_{7}, a_{8}, a_{9}, a_{10}$ need further consideration.

Finally, according to the decision rules $P_{I} \succ B_{I} \succ N_{I}$ and the associated loss of each supplier, we can get the final ranking of 10 suppliers, i.e., $a_{2} \succ a_{9} \succ a_{7} \succ a_{5} \succ a_{3} \succ a_{4} \succ$ $a_{10} \succ a_{8} \succ a_{6} \succ a_{1}$ Thus, the supplier $a_{2}$ is recommended as component supplier. If the enterprise is eager to choose a supplier to supply components, $a_{2}$ can be reluctantly selected. Otherwise, the enterprise needs to further investigate and collect more information to select the optimal supplier to avoid potential risks and maximize the interests of the enterprise.

\section{Conclusions}

With the complexity of society and the actual need of real life, in the face of all kinds of conditions, the company needs to choose the optimal scheme of minimum risk, its purpose is to maximize interest with the company, so it belongs to MADM problems, on the other hand, the decision results of MADM problem is further subdivided into three regions, which help the company to choose a plan, do not choose options or consider options further. Thus, the MADM approach is combined with 3WD to enable all alternatives to be not only sorted, but also to reduce risk. The results and analysis are as follows:

1. There are four evaluation indicators in the supplier selection problem, which are technical level $\left(A_{1}\right)$, service level $\left(A_{2}\right)$, business ability $\left(A_{3}\right)$ and enterprise environment $\left(A_{4}\right)$. Business ability $\left(A_{3}\right)$ is the attribute with the highest influential weight and the ability of finance, supply, cooperation as well as development and economic efficiency are various aspects of business ability. In addition, product development capability, product quality and reliability are included in the level of technology; price, reputation, aftersales service satisfaction belongs to the service level; enterprise environment primarily covers the compatibility of economic and technological environment, geographical environment and enterprise culture.

2. Through the 3WD-MADM method, since $a_{2}$ is the first in the whole sort and the risk is minimal, the supplier $a_{2}$ is the best choice.

In this paper, a new 3WD model, applied to the supplier selection, has been put forward aiming to solve IF MADM problems. On the basis of IF-ELECTRE-I method, an outranking relation has been introduced and the outranked set has been constructed. A hybrid information table has been put forward by the combination of IF MADM matrix and loss function table. Then, the corresponding 3WD model has been investigated. We have demonstrated the effectiveness of the 3WD method though applying the proposed method to the problem of supplier selection. This study does not consider the availability of linguistic variables, so future papers will focus on establishing various new decision models by combining hesitating intuitionistic fuzzy environments, linguistic variables and rough sets, so as to provide more academic and practical values for many problems. 
Author Contributions: Investigation, L.F.; Supervison, Z.G. Both authors have read and agreed to the published version of the manuscript.

Funding: This work is supported by National Natural Science Foundation of China (Grant Nos. 12061067 and 61763044).

Institutional Review Board Statement: Not applicable.

Informed Consent Statement: Not applicable.

Data Availability Statement: Not applicable.

Conflicts of Interest: The authors declare no conflicts of interest.

\section{References}

1. Liu, P.D.; Wang, M.H. An extended VIKOR method for multiple attribute group decision making based on generalized intervalvalued trapezoidal fuzzy numbers. Sci. Res. Essays 2011, 6, 766-776.

2. Opricovic, S.; Tzeng, G.H. Extended VIKOR method in comparison with outranking methods. Eur. J. Oper. Res. 2007, 178, 514-529. [CrossRef]

3. Opricovic, S.; Tzeng, G.H. Compromise solution by MCDM methods: a comparative analysis of VIKOR and TOPSIS. Eur. J. Oper. Res. 2004, 156, 445-455. [CrossRef]

4. Liu, P.D.; Zhang, X. Research on the supplier selection of supply chain based on entropy weight and improved ELECTRE III method. Int. J. Prod. Res. 2011, 49, 637-646. [CrossRef]

5. Vinogradova, I. Multi-Attribute Decision-Making Methods as a Part of Mathematical Optimization. Mathematics 2019, 7, 915. [CrossRef]

6. Chen, T.L.; Chen, C.C.; Chuang, Y.C.; Liou, J.J.H. A Hybrid MADM Model for Product Design Evaluation and Improvement Sustainability 2020, 12, 6743. [CrossRef]

7. Zhan, J.M.; Jiang, H.B.; Yao, Y.Y. Three-way multi-attribute decision-making based on outranking relations. IEEE Trans. Fuzzy Syst. 2020, 1-14. [CrossRef]

8. Liang, D.; Liu, D. A novel risk decision making based on decision-theoretic rough sets under hesitant fuzzy information. IEEE Trans. Fuzzy Syst. 2015, 23, 237-247. [CrossRef]

9. Liang, D.C.; Liu, D. Systematic studies on three-way decisions with interval-valued decision-theoretic rough sets. Inform. Sci. 2014, 276, 186-203. [CrossRef]

10. Liu, D.; Li, T.R.; Liang, D.C. Decision-theoretic rough sets with probabilistic distribution. In Rough Sets and Knowledge Technology, Proceedings of the 7th International Conference RSKT 2012, Chengdu, China, 17-20 August 2012; Springer: Berlin, Gremany, 2012; Volume 7414, pp. 389-398.

11. Liang, D.C.; Liu, D.; Pedrycz, W.; Hu, P. Triangular fuzzy decision-theoretic rough sets. Int. J. Approx. Reason. 2013, 54, 1087-1106. [CrossRef]

12. Atanassov, K.T. Intuitionistic fuzzy sets. Fuzzy Sets Syst. 1986, 20, 142-149. [CrossRef]

13. Deng, X.F.; Yao, Y.Y. Decision-theoretic three-way approximations of fuzzy sets. Inform. Sci. 2014, 279, 702-715. [CrossRef]

14. Pedrycz, W. Granular Computing: Analysis and Design of Intelligent Systems; CRC Press/Francis Taylor Publications: Boca Raton, FL, USA; New York, NY, USA, 2013; pp. 1-105.

15. Zadeh, L.A. Fuzzy sets. Inform. Control. 1965, 8, 338-353. [CrossRef]

16. Chen, T.Y. Bivariate models of optimism and pessimism in multi-criteria decision-making based on intuitionistic fuzzy sets. Inform. Sci. 2011, 181, 2139-2165. [CrossRef]

17. Cali, S.; Balama, S.Y. A novel outranking based multi criteria group decision making methodology integrating ELECTRE and VIKOR under intuitionistic fuzzy environment. Expert Syst Appl. 2019, 119, 36-50. [CrossRef]

18. Liu, H.W.; Wang, G.J. Multi-criteria decision-making methods based on intuitionistic fuzzy sets. Eur. J. Oper. Res. 2007, 179, 220-233. [CrossRef]

19. Du, W.S. Subtraction and division operations on intuitionistic fuzzy sets derived from the Hamming distance. Inform. Sci. 2021, 571, 206-224. [CrossRef]

20. Yang, J.L.; Yao, Y.Y. A three-way decision based construction of shadowed sets from Atanassov intuitionistic fuzzy sets. Inform. Sci. 2021, 577, 1-21. [CrossRef]

21. Gao, Y.; Li, D.S.; Zhong, H. A novel target threat assessment method based on three-way decisions under intuitionistic fuzzy multi-attribute decision making environment. Eng. Appl. Artif. Intell. 2020, 87, 103276. [CrossRef]

22. Zou, L.; Lin, H.M.; Song, X.Y.; Feng, K.H.; Liu, X. Rule extraction based on linguistic-valued intuitionistic fuzzy layered concept lattice. Int. J. Approx. Reason. 2021, 133, 1-16. [CrossRef]

23. Ecer, F.; Pamucar, D. MARCOS technique under intuitionistic fuzzy environment for determining the COVID-19 pandemic performance of insurance companies in terms of healthcare services. Appl. Soft Comput. 2021, 104, 107199. [CrossRef]

24. Kumar, M.; Kaushik, M. System failure probability evaluation using fault tree analysis and expert opinions in intuitionistic fuzzy environment. J. Loss Prev. Proc. 2020, 67, 104236. [CrossRef] 
25. Boran, F.E.; Akay, D. A biparametric similarity measure on intuitionistic fuzzy sets with applications to pattern recognition. Inform. Sci. 2014, 255, 45-57. [CrossRef]

26. Li, D.F. Multiattribute decision making models and methods using intuitionistic fuzzy sets. J. Comput. Syst. Sci. 2005, 70, 73-85. [CrossRef]

27. Vlachos, I.K.; Sergiadis, G.D. Intuitionistic fuzzy information-applications to pattern recognition. Pattern Recogn. Lett. 2007, 28, 197-206. [CrossRef]

28. Yao, Y.Y. Decision-Theoretic Rough Set Models.Int. Conf. Rough Sets Knowl. Technol. 2007, 180, 1-12.

29. Yao, Y.Y. Three-way decisions with probabilistic rough sets. Inform. Sci. 2010, 180, 341-353. [CrossRef]

30. Liu, D.; Yao, Y.; Li, T. Three-way investment decisions with decision-theoretic rough sets. Int. J. Comput. Intell. Syst. 2011, 4, 66-74.

31. Yao, J.T.; Azam, N. Web-based medical decision support systems for three-way medical decision making with game-theoretic rough sets. IEEE Trans. Fuzzy Syst. 2015, 23, 3-15. [CrossRef]

32. Sun, B.Z.; Zhang, M.; Wang, T.; Zhang, X.R. Diversified multiple attribute group decision making based on multigranulation soft fuzzy rough set and TODIM method. Comput. Appl. Math. 2020, 39, 45-53. [CrossRef]

33. Wang, J.J.; Ma, X.L.; Xu, Z.S.; Zhan, J.M. Three-way multi-attribute decision making under hesitant fuzzy environments. Inform. Sci. 2021, 552, 328-351. [CrossRef]

34. Xu, Z.S.; Yager, R.R. Some geometric aggregation operators based on intuitionistic fuzzy sets. Int. J. General Syst. 2006, 35, 417-433. [CrossRef]

35. Xu, Z.S. Intuitionistic fuzzy aggregation operators. IEEE Trans. Fuzzy Syst. 2007, 15, 1179-1187.

36. Atanassov, K.T. On Intuitionistic Fuzzy Sets Theory; Springer: Berlin, Germany, 2012; pp. 1-76.

37. Liao, H.C.; Xu, Z.S. Subtraction and division operations over hesitant fuzzy sets. J. Intell. Fuzzy Syst. 2014, 27, 65-72. [CrossRef]

38. Roy, B. Classement et choix en presence de points devue multiples (la methode ELECTRE). Rev. Fr. Inf. Rech. Oper. 1968, 8, 57-75.

39. Wu, M.C.; Chen, T.Y. The ELECTRE multicriteria analysis approach based on Atanassov's intuitionistic fuzzy sets. Expert Syst. Appl. 2011, 38, 12318-12327. [CrossRef]

40. Yao, Y.Y. Three-way decision and granular computing. Int. J. Approx. Reason. 2018, 103, 107-123. [CrossRef] 